\section{Commentary: The older and sicker you are, the faster you die!}

\author{
Jean Bachet, MD, FEBCTS
}

Chung and colleagues ${ }^{1}$ report on an interesting analysis of the results of aortic arch surgery in 3 categories of age in a very large cohort of patients.

As could be expected through common sense, history, and literature as well as daily practice, this analysis shows that, obviously, the older the patient, the more severe his or her postoperative condition and the greater the risk of mortality, stroke, and other complications.

The interesting point of the present article is that it exactly defines through precise data and percentages the increase of risk in 3 defined categories of age and according to the elective or emergent condition of surgery.

However, readers may be somewhat disappointed by the fact that no threshold of undue risk was defined and that it is not indicated how to make the decision to electively operate or not on a patient beyond age 75 years, except through the traditional and usual analysis of existing comorbidities.

It is also noteworthy that in the 3 age categories that were studied, $75 \%$ of the patients underwent hemiarch replacement. One may wonder whether the analysis of the patients undergoing total arch replacement would have demonstrated the same differences in the 3 age categories. Or if the authors had more extensively outlined or discussed the differences between patients operated on electively or in emergency. Those in the latter group generally have an increased rate of acute dissection, aneurysm rupture, and the like, such that the surgical risk, even in patients older than 75 years, should not be determinant in the surgical decision, except for very old patients (nonagenarians?) and patients in extreme preoperative condition.

It seems that the main problem of the present study consists of the choice of age as the single discriminant

\footnotetext{
From Association for the Development and Improvement of the Techniques of Screening and Treatment of Cardio-Vascular Diseases (ADETEC), Suresnes, France.

Disclosure: Author has nothing to disclose with regard to commercial support.

Dr Bachet is retired.

Received for publication Feb 20, 2020; accepted for publication Feb 20, 2020; available ahead of print March 12, 2020.

Address for reprints: Jean Bachet, MD, FEBCTS, ADETEC, 1 place Marcel Legras, 92150 Suresnes, France (E-mail: jean.bachet@yahoo.fr).

J Thorac Cardiovasc Surg 2021;162:767-8

$0022-5223 / \$ 36.00$

Copyright (C) 2020 by The American Association for Thoracic Surgery

https://doi.org/10.1016/j.jtcvs.2020.02.102
}

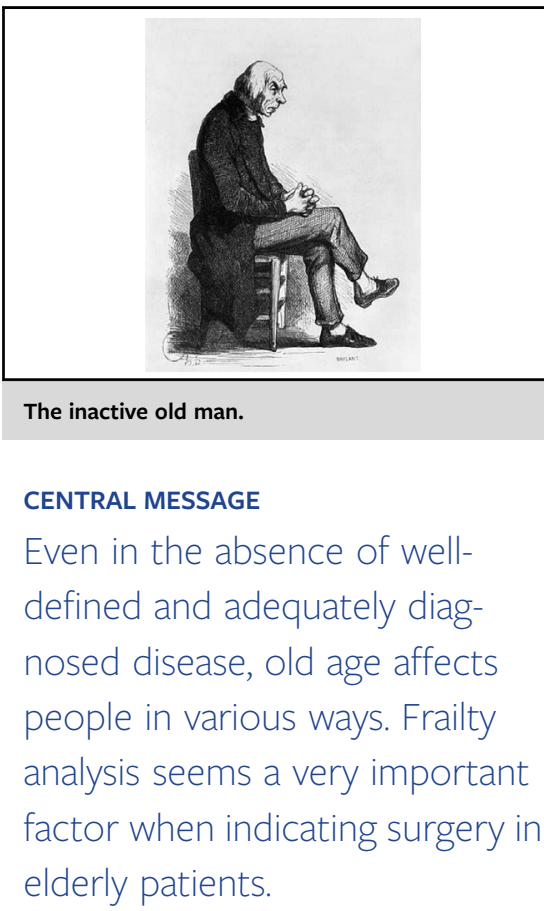

factor for the reported results. Indeed, beside clearly defined and diagnosed comorbidities, age appears to be only 1 among many factors that may influence the surgical risk in elderly patients as compared with younger ones. Elderly patients are certainly not a homogeneous group. We all know or daily observe people in their late 70 s or even 80 s who are active intellectually and physically and who live a rather normal life without difficulty. Conversely, we know or may observe people in their early 70s who are impaired physically and limited in their activity despite the absence of any known severe chronic disease or obvious disability. This is due to the fundamental injustice and inequity of genetics, pathology during childhood and youth, social environment, the arduousness and hardship of occupations, lifestyle choices, and other behaviors.

As alluded to by the authors, it seems that the criterion of frailty as it has been developed and is regularly used by geriatricians could be usefully associated to the criterion of age and could help determine more risk factors and more groups, allowing possibly to better determine the proper indication for or absence of surgery.

It is quite understandable that adding factors in a study, especially one that includes so many patients from 10 centers, could be a large and somewhat difficult task. Yet, it would certainly bring more precision and accuracy in the proper determination of surgery in elderly people and could be even more contributory. Could we hope that a 
future study of this kind would complete the present, excellent study and provide precise data on the increase of risk in patients undergoing aortic arch surgery according to their age?

\section{Reference}

1. Chung J, Stevens L-M, Chu MWA, Dagenais F, Peterson MD, Boodhwani M, et al. on behalf of the Canadian Thoracic Aortic Collaborative (CTAC). The impact of age on patients undergoing aortic arch surgery: evidence from a multicenter national registry. J Thorac Cardiovasc Surg. 2021;162:759-66.e1.
See Article page 759.

\section{Commentary: Aortic arch surgery-Acting your age}

\author{
Kanika Kalra, MD, and Edward P. Chen, MD
}

Growing technology and access to health care have led to improved life spans across the world. It is projected that life expectancy may increase over the coming decades from 79.7 years in 2017 to 85.6 years by 2060 in the United States. ${ }^{1}$ With resultant changes in demographics, the need for complex surgical procedures such as aortic surgery in the elderly population is now commonplace. Despite technical advances and improved outcomes in proximal aortic surgery, the complexity of these operations still predispose the elderly to higher risks of stroke, delirium, and renal failure.

Operative mortality from aortic surgery in the elderly ranges from $3.7 \%$ to $37 \%$ depending upon age and elective versus emergency nature of the operation..$^{2-4}$ The International Registry of Acute Aortic Dissection demonstrates that age is an independent predictor of mortality in type A aortic dissection. ${ }^{2}$ Data from both the International Registry of Aortic Dissection and the German Registry for Acute Aortic Dissection Type A also suggest that conservative management in this population is associated with more dismal outcomes. ${ }^{2,4}$ Unfortunately, current guidelines do not propose any age cutoff for offering surgery for ascending aortic pathology.

\footnotetext{
From the Division of Cardiothoracic Surgery, Department of Surgery, Emory University School of Medicine, Atlanta, Ga.

Disclosures: Authors have nothing to disclose with regard to commercial support.

Received for publication Feb 25, 2020; accepted for publication Feb 26, 2020; available ahead of print March 12, 2020.

Address for reprints: Edward P. Chen, MD, Division of Cardiothoracic Surgery, Emory University, 5665 Peachtree Dunwoody Rd, Suite 200, Atlanta, GA 30322 (E-mail: edward.p.chen@emory.edu).

J Thorac Cardiovasc Surg 2021;162:768-9

$0022-5223 / \$ 36.00$

Copyright (c) 2020 by The American Association for Thoracic Surgery

https://doi.org/10.1016/j.jtcvs.2020.02.101
}

Check for updates

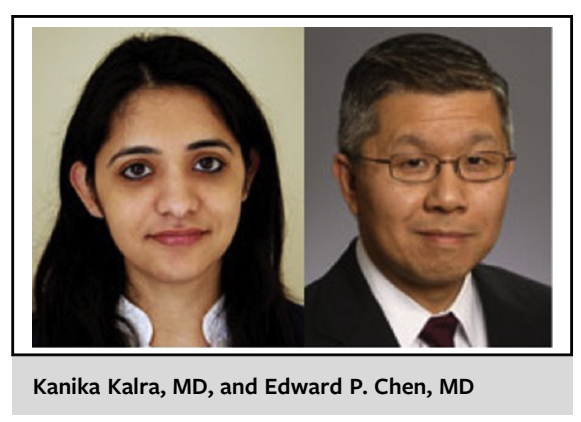

CENTRAL MESSAGE

Operative intervention may be justified in the elderly with

thoracic aortic disease but needs diligent decision-making taking into account frailty, patient expectations, and hybrid approaches.

We congratulate Chung and colleagues ${ }^{5}$ for undertaking an exhaustive retrospective analysis of a large cohort to determine the impact of age on outcomes of aortic arch surgery. The authors compared the outcomes of 2520 patients undergoing aortic surgery with circulatory arrest across 10 centers. ${ }^{5}$ They analyzed 3 groups, age less than 65 years, 65 to 74 years, and greater than 75 years, and demonstrated that age independently predicted in-hospital mortality and morbidity defined by the Society of Thoracic Surgeons defined composite, but not stroke, in both elective and emergency settings. Fifty-seven percent of patients aged 75 years or more experienced at least 1 serious complication after emergency repair. The oldest cohort experienced an inhospital mortality of $8.6 \%$ in the elective setting and $22 \%$ in the emergency setting.

This study provides important insights into operative outcomes across different age groups, but lacks valuable information regarding long-term survival and quality of life, which are important considerations in the elderly 